\title{
Introduction to the special issue on Mobility and family: Increasing job mobility - Changing family lives
}

Mobility is one of the core topics of sociology from the start. It is associated with modern society, especially with late modern societies in the globalised world (Urry 2007; Sennett 1998; Durkheim 2007; Tönnies 1988). After decades of being interpreted as the core driving force in transformation processes by sociological theories, mobility recently has become a popular object for empirical research (Schier 2010; Schneider/Collet 2010; Schneider/Meil 2008; Stutzer/Frey 2008; Kesselring/Vogl 2008; Schneider/Limmer/ Ruckdeschel 2002). Results confirm at least one assumption of the theories of late modernity: People in Europe have become more mobile over the course of the last two decades (Lück/ Ruppenthal 2010; Haas/Hamann 2008; Haas 2000).

What are the consequences for families? It has been assumed that increasing mobility fosters weak bridging ties and hinders strong binding ties (Viry/Kaufmann/Widmer 2009; Granovetter 1982). Optimistic interpretations emphasise the first part of this assumption (e.g., Giddens 1990; Beck 1997). They claim that individuals have more freedom and more opportunities to built social ties according to their personal preferences, even over large distances. Pessimistic interpretations emphasise the second part of the assumption (e.g., Sennett 1998; Baumann 2000). They warn that individuals become uprooted and socially isolated, even disoriented. In any case, the prophecies sound threatening for families. Families certainly represent strong ties and require immediate face-to-face time for their maintenance. Mobility implies leaving a common home and interrupting common face-to-face interactions for certain phases. We therefore must assume that mobility is a potential hindrance to building up and maintaining partnerships, becoming a parent, and realising a good quality of family relations.

This is reason enough to focus empirically on the relationship between mobility and family life. Does mobility affect family life at all? If so, which aspects of family life are concerned, in what way, and under which circumstances? What can we deduce from current trends in mobility regarding the future of European families?

The arguments above are a very rough approach to the topic. Several differentiations need to be made. First, the term mobility is being used for a series of different phenomena. They certainly are related to each other, but they also certainly may have different 
impacts on family life. What kinds of mobility are there? And which mobility is most relevant in terms of studying influences on family life?

\section{Multiple meanings of the term mobility}

The most general use of the term mobility refers to social change ("soziale Veränderung" Bonß/Kesselring 2001: 177). It is even used as a synonym for change of any kind. The phrase cultural mobility, for example, is used by some authors for describing cultural change (e.g., Greenblatt et al. 2009: 12ff.). Following this practice, mobility seems too broad to use for any thesis or empirical operationalisation.

Mostly the term is used somewhat more specifically by referring to a change in position. One understanding is spatial mobility: the movement of people or things through geographical space. This still includes a large variety of phenomena, such as the export and import of goods or the travel of people from home to work or to a vacation destination. Aside from differentiating between who or what is moving, it is important to distinguish between purposes of mobility. Since private reasons to travel are, to a large extent, expressions of individual interest, they are more likely to be affected by the family situation than to affect family life. Therefore, they are of lesser interest in this context than professional reasons. Also the travel of individuals is more likely to affect families than the travel of goods. Of central interest, therefore, is the mobility of people for job-related reasons, referred to by the term job mobility or job-related mobility (Limmer/Schneider 2008: 13). The consequences for families, as indicated at the beginning of this article, are multiple and potentially grave.

Another phenomenon that is frequently addressed by the term mobility is social mobility: the change of position of human beings within the social structure of a society (e.g., Goldthorpe 2003). A similar understanding is, again, connected to the term job mobility. This term is common for referring to a change of jobs, to transitions from employment to unemployment or non-employment, as well as to re-entries into the labour market (e.g., DiPrete et al. 1997). These mobilities no doubt have strong impacts on family lives. For example, the increasing risk of employees' losing a job or moving downwards socially when changing jobs may be an important reason for an increase in female labour market participation (Hofmeister/Blossfeld/Mills 2006).

A fourth phenomenon addressed by the term mobility is virtual mobility: the movement, or rather the spread, of information from one individual to another through space (e.g., Kenyon/Lyons/Rafferty 2002). Mostly, the term is used for communication using technical appliances in a non face-to-face situation over large distances. There are not many grave, but a few possible, consequences for family life: Partnership formation may occur more often interregionally or internationally (Schneider/Ruppenthal/Lück 2009; Döring 2000), and partner relationships can be maintained over large distances for longer periods of time. Also work from home is easier to organise in knowledge-based jobs, which - in turn - may make it easier to combine paid work with family life. This means that virtual mobility may, on the one hand, increase the number of long-distance relationships and the need for family members to become spatially mobile and, on the other hand, moderate the consequences of multilocality and job requirements. 
Finally, some phenomena related to movement through space are also addressed by the term mobility. It can mean the social valuation of people's travelling (Bon $3 /$ Kesselring 2001: 182f) or the ability of individuals, groups, or things to move (e.g., Giddens 1990). To capture this ability theoretically and empirically, the term motility has recently been introduced (Kaufmann 2002; Kaufmann/Bergman/Joye 2004).

Theoretical publications in particular often talk about several or all of these understandings of mobility at the same time. Perhaps a theoretical description could reach a high enough level of abstraction to make such a broad concept useful. However, it is certainly better for empirical research to narrow down its concept to one understanding of mobility. The choice of definition needs to be justified by a theoretical reflection about the way in which mobility is relevant for a given research topic.

Regarding the impact of mobilities on family life, spatial and social mobility are likely to have the most relevance, which means they should be the first choices for study in family research. Given the rather advanced state of the art in the study of social mobility and its consequences on family life, the focus here will be on spatial mobilities - more precisely on job-related movements of people through geographic space. Here, the state of the art of empirical research is very rudimentary.

\section{The relationship between spatial and social mobility}

The practice of summarising several different phenomena under the one term mobility suggests that these phenomena are related, maybe closely enough to be treated as one concept. Is that so? What is the relationship between spatial and social mobility? Is social mobility also involved when spatial mobility is measured - as a cause, as a consequence, or as a second manifestation of the same social processes? Can we assume a statistical correlation between being spatially and being socially mobile?

Answers to questions like these are highly dependent on the perspective. Spatial and social mobility are highly correlated if the process of modernisation in Europe over the course of 300 years is taken into account. Both have increased over time because both are manifestations of the processes of modernisation and individualisation: Individuals have gained a greater degree of freedom, which allows them to move - socially as well as spatially. And for the same reasons, the other understandings of mobility have also increased. Technological progress that occurs within the process of modernisation, of course, fosters mobility as well. This is what the above-mentioned theories state and what legitimises them to treat several, maybe all, mobility phenomena as closely linked (Giddens 1990; Durkheim 2007; Tönnies 1988). However, this is only a correlation on the macro level, looking at a certain chapter of history. It does not imply a correlation among contemporary societies. And it does not imply a micro-level correlation in the sense that an individual who is spatially mobile should also change position in social space or vice versa. Does such a correlation exist?

Spatial mobility has been associated with career advancement. And even if data and empirical evidence are missing, this connection has been plausible over the past decades. As a general rule it can be assumed that any change of jobs is linked to a change of work place. Within a large company or organisation, this may even be true for a change in po- 
sition. A change of work place, again, means a chance that the new work place is far away from the previous one so that the employee either needs to relocate or to start commuting long distances. So, as a general rule, frequent job changes should correlate with being spatially mobile for job-related reasons on the individual level.

In the late 1950s and 1960s, a time of strong and steady economic growth in most European and North American countries, a change in jobs or positions was likely to reflect career advancement. Social downward mobility seldom occurred. Contracts were typically unlimited so that less engaged employees would probably keep their jobs. Whole companies also seldom closed nor did they move their manufacturing to Asia. The job changes that did happen, in comparison, were much more likely to be freely chosen by the employee and to reflect personal improvement. In that sense, social upward mobility probably was a typical cause for spatial mobility.

This correlation does not exist in the same way today (Ruppenthal/Lück 2009). Assuming that it has existed, the disconnection can be explained by the flexibilisation of economies and labour markets. Contracts are more often temporary. Periods of unemployment have become more common among all social strata. As a consequence, among younger cohorts more horizontal job-to-job changes and more exits from and re-entries into the labour market are visible (Mills/Blossfeld/Klijzing 2005). Even social downward mobility in job changes can occur. Job changes should still be a cause for spatial mobility, but they do not necessarily reflect upward social mobility anymore. If social mobility is operationalised as a continuum, with negative and positive values, the statistical correlation between social and spatial mobility may disappear because upward and downward moves neutralise each other in the statistical balance. If it is operationalised as a binary, in terms of changing social position at all or being fixed, there still may be a correlation - if the majority of job changes are not horizontal. This question could be answered empirically only by analysing both mobilities longitudinally in a life-course perspective; however, suitable data so far do not exist.

There are other hypothetically imaginable connections between spatial and social mobility: It would be imaginable that the requirement for being mobile as part of an occupation concentrates on jobs with an especially high or low job prestige or pay. However, there is no theoretical reason for such an assumption, and empirical research reveals much heterogeneity instead: Mobility is required from consultants as well as from truck drivers, from pilots as well as from workers on construction sites. It is certainly true that mobility demands are more likely in specific occupations; but it does not seem as if there is a higher concentration of these occupations in high or in low levels of job prestige. Therefore it is unlikely that social upward or downward mobility increases or decreases the likelihood of being in an occupation that demands mobility.

It would also be imaginable that for various reasons certain social strata tend to have shorter or longer commutes. For example, wealthy people may tend to live outside the cities where land for building houses is available and therefore, on average, have longer commutes. Or wealthy people may live in places with better transportation infrastructure and, therefore, have shorter commutes. But even if such a statistical connection exists, it is specific for time and place: for certain nations and even for regions. Again, there is no good reason to assume a clear or even a general individual-level correlation between spatial and social mobility. 
The linkage between social and spatial mobility is not a general one and cannot be deduced from theoretical reflection. It is variable and can be detected empirically only for specific regions and specific times - as an ongoing challenge for empirical research.

\section{The relationship between spatial mobility and motility}

Motility is the "capacity of a person to be mobile" (Kaufmann 2002: 37). This concept seems quite close to the idea of being spatially mobile, almost in the sense of a tautology. How close is the linkage? How much reason is there to distinguish between mobility and motility?

The factors defining this capacity to be mobile can be sorted into the categories of access, skills, and appropriation. Access includes the available means of transportation (e.g., the existence of railroad networks or the availability of high speed trains) and the practical conditions under which these means can actually be used (e.g., the price for a train ticket or the train schedule). Skills are comprised of the physical abilities (e.g., the ability to walk), the achieved competences (e.g., a driving licence), and the organisational competences that help to make mobility happen (e.g., the ability to research cheap flights). Appropriation is an individual's subjective interpretation of his or her access and skills. It implies whether or not people consider their skills and access to be sufficient for becoming mobile and whether or not they consider mobility worth investing time, money, and energy (idem: $38 \mathrm{ff}$.).

Motility can be regarded as a resource or capital - in the sense of Bourdieu's economic, social, or cultural capital. It is unevenly distributed in society and reflects social inequality. And it is shaped by the socio-economic background. Kaufmann, Viry and Widmer (2010) show that motility correlates with common socio-demographic variables, such as education, income, age, gender, and family situation. Parental family forms, for example, rather go together with restrictions in motility. The interpretation of this fact makes it obvious that the interrelation between motility, mobility, and family life is not unidirectional but reciprocal. Analyses on this issue have to keep in mind that not only may mobility affect family life, but also the family situation may influence whether or not people become mobile.

Kaufmann, Viry and Widmer (2010) also find that motility is statistically related to mobility. It can be regarded as an intervening variable, specifying the causal mechanism between socio-demographic background and spatial mobility. However, none of the interrelations mentioned is a simple proportional correlation. Motility turns out to be not a metric variable or a one-dimensional consistent phenomenon, but rather heterogeneous and multi-dimensional. The authors find six empirically relevant categories of motility, such as "anchored" people or people with "poor access". These are combinations of specific motility aspects. Not only can high access and low skills be combined or vice versa, but also ambivalent combinations of sub-dimensions exist, such as low appropriation of relocation with high appropriation of daily long distance commuting or vice versa. These combinations again correlate with sub-forms of mobility, such as relocation or daily long distance commuting, which will be introduced in more detail below. However, the interrelation is far from being a strong predictor. Thus motility and mobility cannot be treated as one phenomenon. Capability does not necessarily lead to realisation, and restrictions do not necessarily prevent realisation. 
For the relationship between spatial mobility and motility at least three conclusions can be drawn. First, motility increases the chance to become mobile. Second, motility conveys the influence of social context on spatial mobility: Parents, for example, may be less mobile either because they evaluate mobility worse or because they have chosen a place of living with poorer access to transport infrastructure. Third, a specific combination of motility aspects increases the chance that a certain way of being mobile is chosen.

A fourth and a fifth possible relation has not been empirically tested yet: Motility is likely to moderate the consequences of mobility. A daily long distance commute, for example, should cost less time, energy, and stress if the mobile person has good access, high skills, and a positive relation to travel. Fifth, being mobile should act back and increase motility. This is plausible at least for the dimension of skills. By frequently travelling, an individual will, for example, get to know train schedules or the procedure of checking in for a flight in an airport better. It is somewhat plausible even for the dimensions access and appropriation. If an individual is forced to travel, he may buy a car, an annual pass for local public transport, a cell phone, or a laptop. He may move closer to the train station. He may find strategies of dealing with the inconveniences of travelling and begin to appreciate the travel more.

Motility is closely linked to spatial mobility. However, this connection is far from allowing the assumption that the relationship to family life is the same. Motility may be an enlightening background variable to control for understanding how mobility is influenced by and influences family life. However, it must be treated as a complex phenomenon with a reciprocal and complex relationship to mobility.

\section{Characteristics of spatial mobility relevant within family research}

Deciding that job-related spatial mobility will be the focus of this issue is far from determining how mobility shall be operationalised. This decision, again, needs a theoretical reflection how and why spatial mobility is connected to family life. Which characteristics of spatial mobility are responsible for this connection?

The first reason why spatial mobility has an effect on family life is that it may be costly. The expenses for travel are not always carried by the employer - for example, in the case of long distance commuting. In the case of weekly commuting, the employee even has the expenditure of a second residence. These expenditures may reduce the disposable household income very significantly with all the consequences for family life that income differences have. For example, the neighbourhood and the quality of housing (in the first residence) may be less family friendly, and the choices of kindergartens or schooling may be reduced. This aspect is very relevant; however, operationalising mobility (only) in terms of its costs is less likely to produce many new insights since the relationship of disposable income and family life has already been studied.

A second reason why spatial mobility affects family life is that it requires physical and mental energy. The energy that travel requires varies according to circumstances. For car drivers traffic jams, bad road conditions or bad weather may make the journey stressful. Travel by train requires more energy if many changes and tight connections are involved, if luggage is heavy, if train cars are packed, or if seats are uncomfortable. If the travel time fa- 
tigues the mobile person, the consequence may be that he or she will not be in the mood to make conversation at home and will not be able to support the family as much as if the mobility were not involved. Family relations and family organisation may suffer.

The third and strongest reason why spatial mobility has an effect on family life is, as explained earlier, that it causes relatively long periods of absence: The absence of one partner in a couple may prevent family planning and family formation; the absence of one member of a family may burden the organisation of family responsibilities and the quality of family relations. Contributions to childcare or housework, as well as the face-to-face interaction necessary to maintain intimate relationships, are reduced. Such interaction is not simply difficult because the mobile person may not be concentrated enough for significant support or for good conversation; rather, through absence it is made impossible. Therefore, the duration of absence is an important aspect in predicting how grave the consequences of the mobility will be. In addition to the duration, the predictability and the regularity of mobility are also relevant for its consequences. The more regular and foreseeable the mobility, the better it can be integrated into the family and into private life.

An example may illustrate that the duration and the frequency of mobility are not a self-evident way of operationalising spatial mobility: A local bus driver is highly spatially mobile. He spends several hours each day moving through geographical space, travelling many kilometres. However, his presence at home will not be reduced by his mobility at all, and his family will not notice the difference from an employee working in an office or shop. Therefore, it does not make sense to consider him mobile in this context. The situation is quite different for the driver of a chartered bus who takes groups of people on vacation. He will be gone not only during the day, but also for several days and nights in a row until the vacation tour is over. His mobility causes a long period of absence.

The same is true for truck drivers, seamen, pilots, and other professions that deal with transporting people or goods. A similar situation occurs when people need to work in (immobile) workplaces that are too distant from home to return each night. This is a typical situation for workers on varying construction sites or for consultants who work for varying customers. It is also true for weekend commuters in any job that requires working in a fixed workplace distant from home, for example, because they have a partner who has a job near home and is unwilling to move.

A long period of absence from home that affects family life does not necessarily need to involve overnight travel. It is entirely possible that a daily long-distance commute can make a noticeable difference. The commuter will need to leave the house early. He will not be able to take the children to school, and there will not be time for a chat with family members over breakfast. In the evening he will return relatively late, maybe too late to get involved in household tasks or to kiss the young children goodnight.

The common criterion of these examples is that ongoing recurring forms of spatial mobility are causing absences beyond the usual daily work hours and the usual duration of a daily commute. "Beyond the usual," of course, is a vague criterion. It needs to be defined with respect to the overall distribution of commuting durations (not of commuting distances); however, that still leaves more than one possible definition.

Job-related spatial mobility can occur in a completely different form - as residential mobility. Instead of continually commuting a long distance between home and the workplace each day or each week, one can move the entire household and take a new home 
that is close enough to the workplace for a "normal" daily commute. Is this form also relevant in the context of family research? It may well be, but for different reasons. The relocation does not reduce the face-to-face time between members of the nuclear family. It may, however, burden other social ties by increasing the distance to members of the extended family, as well as to close friends and other significant people. The children may lose playmates; the grandparents may now be too far away to take care of their grandchildren. Also the old school, the sports club, the favourite pub, etc., will be too far away. The family loses a social network as a support and the local infrastructure in which it was organised. It therefore has to reorganise itself and build up a new social network or get along with less support. This certainly can have effects on family life. The criterion in this case is not the duration of absence of one family member, but the fact that the distance between the new and old homes is too large to bridge daily.

These reflections allow several methodological conclusions. Generally it is worthwhile to study several mechanisms: the consequences of the expenses for mobility, of mobility effort and stress, of long distance relocations as well as the consequences of phases of absence due to mobility for family life. In this context all four mechanisms are of interest, as the articles in this issue will reflect. If possible, the single effects could be empirically estimated by controlling them simultaneously in multivariate analyses. However, since all four characteristics of mobility are likely to correlate with each other, it will usually not be possible to isolate any single effect. Then, at least on a theoretical level, interpretations need to reflect that the relation between mobility and family life is complex, and several mechanisms may explain an existing statistical relation causally. It is even more complex since counter-directional effects of family life on mobility also exist, such as the above sketched influence of parenthood on restrictions in motility. Several other connections are imaginable: For example, in dual earner couples it is more likely than in single earner couples that (at least for one partner) a long-distance commute becomes necessary (cf. the article of Collet and Bonnet in this issue).

\section{Definition and further differentiation of "job mobilities"}

The previous section has demonstrated two things: First, even the specification of mobility as the job-related spatial mobility of people leaves a heterogeneous range of mobilities that requires further differentiation. The most fundamental distinction is the one between recurring and residential forms of mobility. Within recurring mobilities we need to distinguish those with more or less frequent and with shorter or longer periods of absence; especially those job mobilities that involve overnight travel must be distinguished from daily long distance commuting. And we need to consider circumstances such as effort and costs of travel.

The second insight from the previous section is that at least four characteristics can be considered for operationalising job-related spatial mobility in the context of family research. In order not to make the operationalisation too complex, only two aspects will be taken into account here: absence and relocation. In the following, people will be called "mobile" if at least one of the following four criteria is fulfilled":

1 More precise definitions can be found in Limmer/Schneider (2008). 
- A person has spent 60 overnights or more away from home, for occupational reasons, during the last 12 months.

- A person lives in a long distance relationship in which both partners maintain separate households predominantly for job-related reasons.

- A person commutes daily with an overall commuting time of at least two hours (one hour each way as a mean).

- A person has changed his/her main place of residence over a distance of at least $50 \mathrm{~km}$, predominantly for occupational reasons.

This operationalisation, however, does not imply that the costs and effort of travel are not also aspects that need to be considered within the analyses and interpretations. And, to make things even more complex, there are further aspects of relocating and of the absence caused by recurring mobilities that very likely play a role, too. Within residential mobilities - aside from the distance to the previous place of living - it may be relevant whether or not a relocation occurs across a national or a language border or only across regions, as well as whether it is a "one way" relocation, whether it involves a foreseeable return later on, or whether it is already a return move after an assignment. Within recurring mobilities - aside from the frequency or rhythm and the duration (daily or overnight) of travel - the regularity and the predictability may affect family life.

Being unable to contribute to childcare or housework is not simply a question of the number of hours at home. Often responsibilities require planning ahead. A couple will probably decide in the morning who will pick up the child after choir practice in the evening. If it is unforeseeable whether or not one partner will be back in time to do this, it will need to be the other partner who takes on the responsibility. Tight train connections that can be missed, busy highways that may congest, and also flexible mobility requirements on the job introduce such uncertainties. These uncertainties may be graver if their range includes not only hours of return, but also the question of whether or not a person will leave at all and for how many days or weeks. Such unpredictable absences are typical, for example, of military staff. It is a burden for couples and families and a frequent reason for separation (Wendl 2005).

Not as grave as the unpredictability but also highly relevant is the (ir)regularity of mobility and of absences. Given the large range of chores within family life, couples tend to organise many of them in terms of a permanent distribution of responsibilities. For specific tasks, such as grocery shopping, cooking, or repairs around the house, it is mostly the same partner who takes care of them (with gender roles serving as an orientation). This reduces the effort of daily coordination and negotiation. Irregular absences, such as are typical for flight crews or salesmen, complicate or prevent such a general division of responsibilities. Then the frequent spontaneous reorganisation and coordination becomes a challenge of its own. Irregular absences also complicate the establishing of family routines. These are important for the maintenance of family relations. Children may appreciate a bedtime story each evening; the partners may enjoy going out for a dance class each Thursday. Families with an irregularly mobile member are restricted in this regard. 


\section{Increasing mobility - Increasing relevance}

Job-related spatial mobility, defined as described above, is a widespread phenomenon among Europeans. In 2007 a six-country survey - including Germany, France, Belgium, Switzerland, Poland, and Spain - found that almost one in five (18\%) fulltime employees aged 25 to 54 is currently mobile; and roughly one in two (48\%) has experiences with mobility either currently or in the past (Lück/Ruppenthal 2010). The percentages vary only slightly between the six countries. Given a certain heterogeneity among the countries included in the survey, there are good reasons to believe that the situation is similar also in other parts of Europe that were not included.

In all six countries recurring mobilities are also more frequent than residential mobilities (idem). According to the study, 5\% of fulltime employed people aged 25 to 54 are frequently away overnight; $7 \%$ are daily long-distance commuters; $3 \%$ have relocated; and $2 \%{ }^{2}$ are mobile in more than one way. As mentioned earlier, commuting appears to be a common strategy for avoiding the consequences of an interregional relocation: the loss of contacts to the extended family or to friends, the loss of a local social network as a support, and the loss of a local infrastructure. Europeans must be considered sedentary, also because of an emotional attachment to their home regions. Recurring mobilities serve as a compromise between the reluctance to be mobile and the necessity of doing so. However, as sketched above, the compromise has the downside of introducing pressure on the immediate family relations.

What becomes more frequent becomes more relevant. As mentioned in the beginning of this article, there is empirical evidence that mobility has increased during recent decades. And this is particularly true for recurring mobilities (Lück/Ruppenthal 2010; Haas/Hamann 2008; Haas 2000).

Without denying that modernity or postmodernity may be theoretical frameworks that are able to explain this trend in the long run, for the recent increase several specific causes have been identified (Ruppenthal/Lück 2009; Schneider/Ruppenthal/Lück 2009). A first cause is the globalisation of economic relationships. With the fall of the iron curtain and the rise of East Asian economies, with the restraints of international trade and of employment being reduced, and with the transport of goods being cheap in comparison to wage differences, economic collaboration and product as well as labour markets are becoming more international. As a consequence, more people have to bridge larger distances for contacting customers or colleagues. A second cause is the flexibilisation of labour markets. In order to react to market developments faster and to increase the pressure on employees, contracts are more often time limited or employees are even outsourced as formally self-employed contractors. This increases the number of job changes in individual job careers so that workplaces also change more frequently and mobility becomes necessary. It also reduces the ability to plan careers in the long run so that a large distance to a new workplace will be bridged by commuting rather than by the more binding investment of relocation. A third cause is the increase of female employment (Lück 2009). With more couples being dual earners, the choice of the residence has to take into account two workplaces instead of one. This makes it less probable that a long distance to a new

2 The percentages do not add up to $18 \%$ because of rounding. 
workplace can be solved by relocation. If the two workplaces are far away from each other, at least one partner needs to be a weekly or a daily long-distance commuter.

Not all parts of societies are affected by mobility in the same way. Younger cohorts are affected much more than elder cohorts are - which documents the increase. This difference is especially visible in Poland, an indication that the protection of labour markets and involvement in international markets matters. People in time-limited work contracts are more likely to be mobile than other employees, which confirms that the flexibilisation of labour markets may be part of the explanation for the mobility increase (Lück/Ruppenthal 2010).

There are other characteristics that identify specific "risk groups." Beyond the cohort differences, mobility is typical for young adults. They are not as well established in their job career as are older people, so that they probably cannot refuse mobility requirements as easily. They are also not as strongly committed to a certain place of living since they seldom are homeowners or parents. In fact, parents are also less likely to be mobile than are people without children. People with a partner are less likely than those without. These are the first indications that mobility does have an effect on family life - and vice versa.

\section{Consequences of mobility for family lives}

These interrelations are studied in detail in the articles in this issue. All articles work with the mentioned data collected in a six-European country survey in 2007. The overall sample size is $n=7220$. The data are representative for the residential populations of the six countries, aged 25 to 54 years. An oversampling of mobile people allowed analysing mobility in a differentiated way. A design weight corrects the oversampling for descriptive analyses (Huynen et al. 2008; Huynen et al. 2010).

Gil Viry, Eric Widmer and Vincent Kaufmann ("Does it matter for us that my partner or I commute?") focus on the consequences of mobility for the partnership quality in the French, German and Swiss context. They find few effects of mobility or of the form of mobility as such. What turns out to be relevant is the process by which a person becomes mobile and the circumstances that accompany this process. In brief, one can state that two types of processes are associated with high conjugal satisfaction and few conjugal conflicts: first, when mobility was started willingly, motivated by own interests and second, when mobility was forced by the job market but families and networks did not intervene in the decision making. This result is clearer for Switzerland and Germany than for France, which reflects that certain conditions on the macro level (and certainly also on the micro level) moderate the effects on partnership quality.

Gerardo Meil ("Geographic job mobility and parenthood decisions") asks whether and under which circumstances mobility affects the emergence, development, and timing of parenthood. He finds that mobility does have effects, at least if the period of being mobile overlaps with the life-course stage of family formation and if it is long enough. For men, mobility leads to a postponement of family formation rather than to childlessness. For women, the effects are much stronger. Mobility increases both: the risk of remaining childless as well as the age at first birth. Meil also interprets the fact that relatively few women are mobile as a consequence of persisting gender roles, defining family work as a 
female responsibility and thereby intensifying the conflict between mobility and family planning, especially for women. Long periods of mobility for both men and women may reduce the family size.

Beate Collet and Estelle Bonnet ("Decisions concerning job-related spatial mobility and their impact on family careers in France and Germany") compare mobility and decisions regarding becoming mobile in France and in Germany from a couple's perspective, using quantitative and qualitative data. They find that mobility is more frequent among dual earner couples than among male breadwinner couples. The connection between mobility and family situation is stronger in Germany than in France. Becoming mobile can be either a common decision or a decision of the one mobile partner only. If the latter is the case, men have different motivations for doing so than women have, and women in France have different motivations than women in Germany. The results reveal a complex interrelationship between nationally differing gender roles, family cultures, and mobility patterns.

Detlev Lück ("Walking the tightrope") raises the question of how mobility affects the challenge couples face in combining two careers with having a family. He finds that couples tend to be childless rather than give up one partner's job if both goals are incompatible. Job mobility reduces the ability of couples to combine both, similar to the way working overtime or other unfavourable circumstances do; but job mobility does so rather more than other circumstances. This is especially true if the woman is mobile. There is also evidence of influence if the man is mobile, but these effects are not nearly as strong. The national context matters in several ways: In certain countries the compatibility of professional work and parenthood is generally easier than in others. In certain countries job mobility reduces this compatibility more severely than in others, and in certain countries the gender differences on this effect are stronger than in others. The reasons for these effects can be found in culture - for example, in the social construction of gender roles - as well as in policies and infrastructure - for example, in the predominant forms of mobilities or in the availability of public childcare.

All in all, the findings document that causal relations between job-related spatial mobility and family life are never simple. Often effects are rather connected to subtle aspects, such as the circumstances of becoming mobile, than to obviously visible criteria. They always appear as interaction effects. And mostly macro and micro level circumstances, as well as structural and cultural conditions, need to be considered. The timing within the life course matters as well as the gender, the working conditions may matter as well as the job situation of the partner. Gender roles and national family policies need to be taken into account.

Mobility does have effects on family life. And most of these effects demonstrate that with increasing mobility, family foundation becomes more difficult to realise and family life becomes more difficult to organise. However, the relation between mobility and family life is moderated by many circumstances and probably can be actively moderated.

\section{References}

Bauman, Z. (2000). Liquid modernity. Cambridge: Policy Press.

Beck, U. (1997). Ortspolygamie. In: U. Beck, Was ist Globalisierung? Frankfurt am Main: Suhrkamp, pp. 127-135. 
Bonß, W. \& Kesselring, S. (2001). Mobilität am Übergang von der Ersten zur Zweiten Moderne. In: U. Beck \& W. Bonß (Eds), Die Modernisierung der Moderne. Frankfurt am Main: Suhrkamp, pp. 177-190.

DiPrete, T. A., de Graaf, P. M., Luijkx, R., Tahlin, M. \& Blossfeld, H.-P. (1997). Collectivist versus individualist mobility regimes? Structural change and job mobility in four countries. American Journal of Sociology, 103, (2), pp. 318-358.

Döring, N. (2000). Romantische Beziehungen im Netz. In: C. Thimm (Ed.), Soziales im Netz. Sprache, Beziehungen und Kommunikationskulturen im Internet. Wiesbaden: Westdeutscher Verlag, pp. 39-70.

Durkheim, É. (2007). De la division du travail social. Paris: PUF (first published in 1893).

Giddens, A. (1990). The consequences of modernity. Cambridge: Polity Press.

Goldthorpe, J. H. (2003). Social mobility and class structure in modern Britain. Oxford: University Press.

Granovetter, M. S. (1982). The strength of weak ties: A network theory revisited. In: P. V. Marsden \& N. Lin (Eds), Social structures and network analysis. Beverly Hills: Sage, pp. 105-130.

Greenblatt, S. et al. (2009). Cultural mobility. A manifesto. Cambridge: University Press.

Haas, A. (2000). Regionale Mobilität gestiegen: Arbeitsmarktausgleich. Bei einem Betriebswechsel werden immer öfter größere Entfernungen überwunden - gerade auch von Arbeitslosen. Nürnberg: Institut für Arbeitsmarkt- und Berufsforschung der Bundesanstalt für Arbeit (IAB Kurzbericht No. 4/ 18.4.2000).

Haas, A. \& Hamann, S. (2008). Pendeln - ein zunehmender Trend, vor allem bei Hochqualifizierten. Nürnberg: Institut für Arbeitsmarkt- und Berufsforschung (IAB-Kurzbericht 6/2008).

Hofmeister, H., Blossfeld, H.-P. \& Mills, M. (2006). Globalization, uncertainty and women's mid-career life-courses: A theoretical framework. In: H.-P. Blossfeld \& H. Hofmeister (Eds), Globalization, uncertainty and women's careers. An international comparison. Cheltenham: Edward Elgar, pp. 3-31.

Huynen, P., Hubert, M. \& Lück, D. (2010). Research design. In: N. F. Schneider \& B. Collet (Eds), Mobile living across Europe. Volume II. Causes and consequences of job-related spatial mobility in cross-national perspective. Opladen \& Farmington Hills, MI: Barbara Budrich, pp. 23-34.

Huynen, P., Montulet, B., Hubert, M., Lück, D. \& Orain, R. (2008). Survey design and methods. In: N. F. Schneider \& G. Meil (Eds): Mobile living across Europe. Volume I. Relevance and diversity of job-related spatial mobility in six European countries. Opladen \& Farmington Hills, MI: Barbara Budrich, pp. 47-63.

Kaufmann, V. (2002). Re-thinking mobility. Contemporary sociology. Aldershot, Burlington: Ashgate.

Kaufmann, V., Bergman, M. M. \& Joye, D. (2004). Motility: Mobility as capital. International Journal of Urban and Regional Research, 28, (4), pp. 745-756.

Kaufmann, V., Viry, Gil \& Widmer, E. (2010). Motility. In: N. F. Schneider \& B. Collet (Eds), Mobile living across Europe. Volume II. Causes and consequences of job-related spatial mobility in crossnational perspective. Opladen \& Farmington Hills, MI: Barbara Budrich, pp. 95-111.

Kenyon, S., Lyons, G. \& Rafferty, J. (2002). Transport and social exclusion: Investigating the possibility of promoting inclusion through virtual mobility. Journal of Transport Geography, 10, (3), pp. 207-219.

Kesselring, S. \& Vogl, G. (2008). Networks, scapes and flows - Mobility pioneers between first and second modernity. In: W. Canzler, V. Kaufmann \& S. Kesselring (Eds), Tracing mobilities. Towards a cosmopolitan perspective in mobility research. Aldershot, Burlington: Ashgate, pp. 163-180.

Limmer, R. \& Schneider, N. F. (2008). Studying job-related spatial mobility in Europe. In: N. F. Schneider \& G. Meil (Eds), Mobile living across Europe. Volume I. Relevance and diversity of job-related spatial mobility in six European countries. Opladen \& Farmington Hills, MI: Barbara Budrich, pp. 13-45.

Lück, D. (2009). Der zögernde Abschied vom Patriarchat. Der Wandel von Geschlechterrollen im internationalen Vergleich. Berlin: Edition Sigma.

Lück, D. \& Ruppenthal, S. (2010). Insights into mobile living: Spread, appearances and characteristics. In: N. F. Schneider \& B. Collet (Eds), Mobile living across Europe. Volume II. Causes and consequences of job-related spatial mobility in cross-national perspective. Opladen \& Farmington Hills, MI: Barbara Budrich, pp. 35-67.

Mills, M., Blossfeld, H.-P. \& Klijzing, E. (2005). Becoming an adult in uncertain times. A 14-country comparison of the losers of globalization. In: H.-P. Blossfeld, E. Klijzing, M. Mills \& K. Kurz (Eds), Globalization, uncertainty and youth in society. London: Routledge, pp. 423-441. 
Ruppenthal, S. \& Lück, D. (2009). Jeder fünfte Erwerbstätige ist aus beruflichen Gründen mobil. Berufsbedingte räumliche Mobilität im Vergleich. Informationssystem Soziale Indikatoren (ISI) 42, pp. 1-5.

Schneider, N. F. \& Collet, B. (Eds) (2010). Mobile living across Europe. Volume II. Causes and consequences in cross-cultural perspective. Opladen \& Farmington Hills, MI: Barbara Budrich.

Schneider, N. F., Limmer, R. \& Ruckdeschel, K. (2002). Mobil, flexibel, gebunden. Frankfurt am Main: Campus.

Schneider, N. F. \& Meil, G. (Eds) (2008). Mobile living across Europe. Volume I. Relevance and diversity of job-related spatial mobility in six european countries. Opladen \& Farmington Hills, MI: Barbara Budrich.

Schneider, N., Ruppenthal, S. \& Lück, D. (2009). Beruf, Mobilität und Familie. In: G. Burkart (Ed.), Zukunft der Familie. Prognosen und Szenarien. Opladen \& Farmington Hills, MI: Barbara Budrich, pp. 111-136 (Sonderheft 6 der Zeitschrift für Familienforschung/Journal of Family Research).

Schier, M. (2010): Geschlecht - Mobilität - Multilokalität. In: M. Schier, S. Bauriedl \& A. Strüver (Eds), Geschlechterverhältnisse, Raumstrukturen, Ortsbeziehungen: Erkundungen von Vielfalt und Differenz im spatial turn. Münster: Westfälisches Dampfboot.

Sennett, R. (1998). The corrosion of character - The personal consequences of work in the new capitalism. New York: W. W. Norton.

Stutzer, A. \& Frey, B. S. (2008). Stress that doesn't pay: The commuting paradox. The Scandinavian Journal of Economics, 110, (2), pp. 339-366.

Tönnies, F. (1988). Gemeinschaft und Gesellschaft. Grundbegriffe der reinen Soziologie. Darmstadt, (first published in 1887).

Urry, J. (2007). Mobilities. Cambridge: Polity Press.

Viry, G., Kaufmann, V. \& Widmer, E. (2009). Social integration faced with commuting: More widespread and less dense support networks. In: T. Ohnmacht, H. Maksim, \& M. M. Bergman (Eds), Mobilities and inequality. Farnham: Ashgate, pp. 121-143.

Wendl, P. (2005). Herausforderung Fern-Beziehung? Partnerschaft auf Distanz von Soldaten und deren Partnern bei Auslandseinsätzen. In: G. Kümmel (Ed.), Diener zweier Herren. Soldaten zwischen Bundeswehr und Familie. Frankfurt am Main: Lang, pp. 123-147.

Addresses of the authors/Anschriften der Autoren:

Dr. Detlev Lück

Johannes Gutenberg-Universität Mainz

FB 02, Institut für Soziologie

Colonel-Kleinmann-Weg 2

55099 Mainz

Germany/Deutschland

E-mail: detlev.lueck@uni-mainz.de

Prof. Dr. Norbert F. Schneider

Bundesinstitut für Bevölkerungsforschung (BiB)

Direktor

Friedrich-Ebert-Allee 4

65185 Wiesbaden

Germany/Deutschland

E-mail: Norbert.Schneider@destatis.de 